\title{
Article \\ A GP-Based Hierarchical Objectives Decision-Making Method for Building Energy Efficiency Optimization
}

\author{
Xiang Li ${ }^{1}$, Sha Liu ${ }^{1}\left(D\right.$ and Yichao Sun ${ }^{2, *}$ \\ 1 Department of Construction Management, Faculty of Infrastructure Engineering, Dalian University of \\ Technology, Dalian 116024, China; ShawnLi_LOL@outlook.com (X.L.); sophie_liu@dlut.edu.cn (S.L.) \\ 2 State Key Laboratory of Costal and Offshore Engineering, Faculty of Infrastructure Engineering, \\ Dalian University of Technology, Dalian 116024, China \\ * Correspondence: sunyc@dlut.edu.cn; Tel.: +86-13804248922
}

Citation: Li, X.; Liu, S.; Sun, Y. A GP-Based Hierarchical Objectives Decision-Making Method for Building Energy Efficiency Optimization. Buildings 2022, 12, 52. https: / / doi.org/10.3390/ buildings 12010052

Academic Editor: Gerardo Maria Mauro

Received: 11 November 2021

Accepted: 4 January 2022

Published: 6 January 2022

Publisher's Note: MDPI stays neutral with regard to jurisdictional claims in published maps and institutional affiliations.

Copyright: (C) 2022 by the authors. Licensee MDPI, Basel, Switzerland. This article is an open access article distributed under the terms and conditions of the Creative Commons Attribution (CC BY) license (https:// creativecommons.org/licenses/by/ $4.0 /)$.
Abstract: Building energy efficiency, which is critical in reducing environmental impact, has become one of the most important objectives of building designs. In order to precisely express the goals of building designs, and help decision makers estimate the ultimate performance of design schemes in advance when searching for the optimal building design, the Goal Programming Model (GPM) is introduced in this study to provide a solution for explicit design objective delivery and multistakeholder involved decision-making support. In this proposed method, EnergyPlus ${ }^{\mathrm{TM}}$ works as a simulation engine to search for the relationship between design parameter combinations and building energy consumption. Simultaneously, Genetic Algorithm (GA) is used to improve the efficiency of overall building energy performance optimization by processing multiple iterations. A case study with five possible design scenarios was dedicated in this study to implement the proposed optimization method, and the optimization results verified the capacity of the established GP-based optimization method to satisfy various design requirements for decision makers and/or stakeholders, especially in facing the hierarchical objectives with different priorities. In this case, the envelope-related variables, including the exterior wall and window, serve as optimization objectives. The optimization is carried out under the ideal air conditioning system, considering different energy usage patterns. Meanwhile, comparing with the vague and restricted expression of objectives in multi-objective optimization, the proposed GP-based optimization method provides explicit trade-off relationships among various objectives for designers, which improves the practical value of the optimized designs, so as to ensure the project success and facilitate the development of green buildings.

Keywords: building design; energy efficiency optimization; decision making; goal programming; genetic algorithm

\section{Introduction}

The oil embargo crisis in the 1970s was a serious challenge in global energy consumption, and new energy challenges emerged afterward [1]. The construction industry is one of the largest consumers of energy and natural resources, and one of the largest sources of the corresponding greenhouse gas emissions. Around $30-40 \%$ of the worldwide primary energy is consumed and around 30\% of the global greenhouse gas emissions are generated in the construction industry [2,3]. Although the building design process does not have a significant environmental impact, it determines nearly $70 \%$ of the environmental performance during the building service life [4]. This was also evident in the International Energy Agency's Energy in the Buildings and Communities Programme (IEA-EBC) Annex 53, where six categories were defined as the influential factors of building energy consumption, including climate, building envelope, building energy and services systems, indoor design criteria, building operation and maintenance, and occupant behavior [5]. 
The first four categories have strong correlation with the decision-making at the design phase; thus, energy efficiency optimization during the design process is very important to the environmental performance of a building during its life cycle.

The building energy efficiency optimization is not merely a simple and direct process to achieve the target levels of energy savings. Generally, the additionally invested costs and energy performance considerations in a building design scheme are two common concerns for desirable building performance [6-8]. Commonly, the building design process is carried out based on the communications between customers and architects. In this process, and when a design is completed, the invested cost is regarded only as an outcome of the design process, not a driver for design optimization [9]. Decision makers (DMs) usually ignore the building energy performance of building designs, due to economic benefits and/or financial concerns. This highlights the fact that the design process needs a more rational and realistic assessment of economic, ecological, legislative, climatic, social and political conditions, traditions, and owner requirements [10]. Therefore, multiple stakeholders such as the building owner(s), architects, engineers, and contractors need to be involved in the building design decision-making activity to express their own preferences [11]. Furthermore, additional stakeholders, such as the tenants and the maintenance and operation team, are also encouraged to participate in the design process. This was proposed by Boecker et al. [12] to engage all the stakeholders at the early stage of the design phase, which can yield more sustainable solutions. Although such a proposal can guarantee the long-term success of the project, the fragmented expertise and varying conflicting requirements of the multiple stakeholders create plenty of challenges for the DMs [13]. It is necessary to decide which objectives should be achieved preferentially, and solve the conflicts among stakeholders. Hence, the building energy efficiency optimization is not merely a technical problem, but also a decision-making process in which improving building energy performance is one of the sub-objectives. This raises two challenges for the DMs before implementing the technical measures: (1) how to identify the relative importance among different design objectives from different stakeholders; and (2) how to precisely express the stakeholders' preferences in mathematical expressions. The aim of this study is to solve these two problems by applying a Goal Programming Model (GPM) coupled with Genetic Algorithm (GA) iteration, which can accurately achieve complex predetermined design goals. The GPM can turn verbal expressions into mathematical expressions according to various design objectives with different importance levels, so as to find satisfactory solutions, which strictly follow the stakeholders' preferences. The GPM enables the relationships between the objectives to be reasonably distributed. Additionally, the proposed GP-based optimization method will address the inherent shortcomings of the multi-objective optimization (MOO) model, and will focus heavily on the decision-making process, rather than only on technical evolution in a solid research framework. This study provides the DMs with a flexible optimization approach, considering various objective relationships and the DMs' preferences for sustainable building designs. Meanwhile, the GPM optimization framework is equally suitable for dealing with various decision-making issues using quantitative variables during lifecycle, considering contradictory stakeholder benefits (e.g., global trade-offs for owners, space utility for architects, construction schedule for engineers, low cost for contractors, and energy conservation for the maintenance and operating team).

\section{Literature Review}

\subsection{Methods for Multi-Objective Building Design}

As a critical process for improving the life cycle energy performance of buildings, building energy efficiency optimization reaches the desired achievement through constantly revising the design schemes [9]. In view of the basic building design requirements, building energy efficiency design not only serves to improve energy performance, but also serves to improve other aspects including economic benefits, environmental impacts, and indoor comfort. The economic benefits mainly include the energy cost and the life 
cycle invested cost [14-16]. The environmental impacts can be improved by minimizing annual energy consumption, carbon dioxide $\left(\mathrm{CO}_{2}\right)$ emissions, and heating and cooling loads as discussed in previous studies [15-19]. In terms of the indoor comfort improvement, researchers focus on how to reduce the uncomfortable time, including optimizing luminous environment, controlling $\mathrm{CO}_{2}$ levels, maintaining preferred ventilation rates, avoiding glare, and adjusting indoor temperature $[14,17,18]$. These goals are usually required to be accomplished in a holistic and integrated manner [20]. Thus, the MOO is generally employed in the optimization for acquiring the set of non-dominated solutions shown in the Pareto frontier, the optimal weighted single objective, the satisfied sequencing solution set, etc. [21]. In addition, the MOO enables designers to consider a large set of design parameter combinations for buildings that are predefined by the constraints, which helps in reaching a satisfactory trade-off among design objectives [22]. To establish the MOO model, the building energy index needs to be evaluated in an appropriate way. Different from the other evaluation criteria, energy index is determined by many correlated variables, such as building orientation, envelope (opaque and glazed surfaces), interior loads (people, lighting, equipment), weather and climate conditions, etc., which have a non-linear effect on energy response of buildings [23].

Since the 1950s, computer applications have been used by building designers, and their usage is exponentially growing in recent decades [24]. Computer applications for building design largely improve the accuracy and efficiency of the MOO, especially by virtue of the simulation engines and evolutionary algorithms. The simulation-based optimization was popular in previous studies reported in the literature due to the complexity of parameter interactions. Simulation tools, which are generally employed to evaluate the optimization results, provide efficient resolutions to define the thermodynamic interaction process with dynamic indoor and outdoor environment [25]. The most commonly used software, such as DOE-2, EnergyPlus ${ }^{\mathrm{TM}}$, DeST, and TRNSYS, has been well-developed for both commercial and academic use [26]. As one of the earliest and widely used simulation engines, a number of tools were derived from the DOE-2, such as eQuest, VisualDOE, and EnergyPro, etc. EnergyPlus ${ }^{\mathrm{TM}}$ is considered as a representative of the dynamic energy simulation engine, which has been used in over $40 \%$ of published core periodicals. Although it does not have any visual modeling interface till now, related work can be realized relying on thermal modeling tools. EnergyPlus ${ }^{\mathrm{TM}}$ can simulate natural indoor temperature, indoor loads, sunlight and shadow, indoor ventilation analysis, and air conditioner energy consumption simulation, etc. DeST, developed by Tsinghua University, is based on an interactive AutoCAD interface to improve energy modelling efficiency. TRNSYS (Transient System Simulation) is developed on the basis of various HVAC system modules. Tuhus-Dubrow [27] applied a GA optimization tool coupled with DOE-2 to optimize the building shape and envelope features. Yu et al. [28] used a multiple-objective genetic algorithm (MOGA) with EnergyPlus ${ }^{\mathrm{TM}}$ to maximize the thermal comfort and minimize the energy consumption of a building design. Similarly, Hamdy et al. [29] proposed a modified MOO research scheme coupled with the IDA Indoor Climate and Energy (IDA ICE) building performance simulation program to minimize both the $\mathrm{CO}_{2}$ equivalent emissions and the investment cost for a two-story house, considering its heating, ventilation, and air conditioning (HVAC) system. Despite the computational burden of running a large number of design alternatives, the simulation engines have demonstrated strong abilities in accurately describing the building energy performance and in revealing the key energy consumption influential factors, compared with other simplified and data-based prediction models such as artificial neural networks $[6,17,22]$. In addition, the emerging optimization algorithms, such as GA, particle swarm optimization (PSO) algorithm, and ant colony optimization algorithm, play a vital role in driving the optimization process and overcoming the difficulties in convergence speed of optimizing. These techniques can greatly improve the efficiency of the "one by one" design trail in the optimization process, which makes it possible to satisfy the requirements of a larger sample set. Since high computational efficiency is desirable for both architects and researchers, the evolutionary algorithm-based 
building energy efficiency design becomes a widely used research framework in recent studies. The GA is typically a stochastic search mechanism that does not need to test all the candidates. GA iterates selectively based on the law of natural selection so that it can greatly improve the optimization efficiency. Murray et al. [30] coupled a degree days simulation technique with a GA model to optimize the thermal energy efficiency in building retrofitting. Yu et al. [28] introduced a novel multi-objective non-dominated sorting GA model (NSGA-II) to optimize the building energy efficiency and thermal comfort. Liu et al. [6] and Kusiak et al. [31] discussed the trade-off between life cycle cost and life cycle carbon emission and the HVAC system optimization, respectively, using PSO. Given the long execution time of EnergyPlus ${ }^{\mathrm{TM}}$, a parallel Python routine was developed to call several EnergyPlus ${ }^{\mathrm{TM}}$ simulations simultaneously [23]. In addition, the computer device helps designers to easily implement the optimization procedure through integrated and user-friendly platforms such as ModelCenter ${ }^{\circledR}$, ModeFRONTIER and GenOpt ${ }^{\circledR}$ [24].

Although the previously mentioned achievements in solving building energy optimization challenges are satisfactory, they mainly focused on the technical innovations, including improving the calculation capacity, meeting multiple goals, and selecting proper design variables. However, the building energy optimization needs improvements in not only the calculation process, but also the decision-making methods. Usually, the MOO supports the decision-making by generating optimal solutions on the Pareto frontier. Facing the different interests and conflicting priorities between diverse stakeholders requires seeking a consensus among the stakeholders, and such issues are usually considered as the MOO model limitations as mentioned previously. In fact, the MOO model is not precise enough, and Salas-Molina et al. [32] pointed out that while most previous studies focused on the improvement of mathematical optimization, the real problem of disintegrated design was not sufficiently mitigated. Two typical problems that need to be addressed are: (1) the relationships among objectives, especially the relative importance of the objectives, are not clearly defined; and (2) the values of optimal solution are difficult to predict. To solve these problems, this study developed a predefined goal-based hierarchical optimization framework by means of GPM.

\subsection{Comparison of GPM and MOO Models}

The MOO model is widely used in energy efficient buildings design and retrofitting $[15,16,22,33]$. There are two common settlement methods to search for the optimal solutions:

1. Converting the objectives into the weighted single objective which usually adopts the methods of weighted sum and weighted Tchebycheff [34]. In order to ensure that specific objectives have similar magnitudes, the normalization techniques must be implemented in advance. Wu et al. [35] introduced the weightings and net present value index to measure two specific objectives of energy saving after retrofitting.

2. Establishing the Pareto frontier as another approach to acquire the optimal solutions, which encompass a series of non-dominated solutions (Pareto optimality) according to the Pareto dominance concept [36]. Solutions on the Pareto frontier have no other feasible solution that can improve one specific solution without degrading at least one another [35]. The Pareto frontier has been employed by many studies to illustrate the trade-off variables and provide optional design schemes [6,22,35,37].

However, since the construction project reflects the benefits of many stakeholders in a complex organization, the conflicts of interest make it impossible to maximize a welldefined utility function [38]. Thus, invalid solutions on the Pareto frontier always exist. Particularly, all of the non-dominated solutions on the Pareto frontier are unpredictable in advance, which indicates that the design results will not satisfy every stakeholder. Consequently, the obtained optimal result is possible to be infeasible. On the other hand, it is difficult to express the stakeholders' preferences only by means of the weighted objectives. This issue raises another two challenges: (1) how to determine the weighting values of the DMs' preferences, and (2) what the percentage weighting of an objective represents. 
On the contrary, the GPM approach emphasizes the acquiring of the satisfactory solution according to specific requirements, and it is an effective approach to convert the DMs' preferences into mathematical expressions. The three main advantages of the GPM approach are:

1. In the construction project, there are some quantitative objectives, such as limited investment, relatively high energy efficiency, and limited construction period. These objectives are usually not equally important. A common verbal expression of the objectives is "the DMs desire to receive the Leadership in Energy and Environmental Design (LEED) gold certification on the basis of the limited investment", which indicates that the cost is obviously of higher priority level than the sustainable indexes.

2. The soft constraints introduced in the GPM approach ensure more flexibility in terms of delivering design requirements, and there are three total possible conditions to describe a soft constraint based on different usages: (a) when the negative deviational variable $d^{-}$exists in a specific objective, it indicates that "the actual value is supposed to exceed the objective as far as possible"; (b) on the contrary, the existence of the positive deviational variable $d^{+}$means to make full use of the existing resources or reduce the use of excessive resource usage; and (c) the last condition that both $d^{+}$and $d^{-}$exist underlines the shorter distance from the deviational variable to the objective rather than the specific approaching directions. The objective requires an exact match of both the actual value and the objective value.

3. The hard constraints and the weighted constraints in the same priority level can be involved in the GPMs, expanding the application scenarios.

In the GPM approach, the core tasks of the DMs rationally distribute the limited resources in order to fulfill the preset objectives. The GPM search embodies the underlying satisfying philosophy when a series of objectives are proposed in advance. Although some objectives are impossible to strictly achieve, the GPM approach still has its advantage in approaching preset objectives as far as possible by its highly flexible expression and implication. It provides the DMs with a new perspective to deal with the conflicting goals in the decision-making process.

\section{Research Methodology}

\subsection{Goal Programming Modeling}

\subsubsection{Brief Introduction}

The GPM is a multi-objective programming technique derived from the concept of objective satisfying, in which Simon [39] supposed that the maximized utility function is not the ultimate goal in the complex organizations due to the conflicts of interests and the incompleteness of available information [38]. In view of Simon, to build a reliable mathematical expression of the DMs' preferences is almost impossible in this context. As a result, DMs try to achieve a series of objectives as closely as possible. The GPM is the appropriate technique to search for satisfactory solutions.

Charnes and Cooper [40] first introduced the explicit definition of the GPM in 1961. Afterwards, Lee [41] and Ignizio [42] made great contribution for an impressive advancement of the GPM application and related technical improvements in the 1970s, and until the end of the 20th century, the GPM was still the most widely used multi-criteria decision-making technique [43]. Recent studies still emphasized the advantages of the GPM in avoiding unfeasible solutions [32,44]. The algebraic representation of the GPM is shown as:

$$
\begin{gathered}
\min z=\sum_{j=1}^{n} P_{j} \sum_{i=1}^{m}\left(w_{i j}^{-} d_{i}^{-}+w_{i j}^{+} d_{i}^{+}\right) \\
\text {s.t. }\left\{\begin{array}{l}
g_{h}(x) \leq 0, h=1,2, \ldots, H \\
f_{i}(x)-d_{i}^{+}+d_{i}^{-}=S_{i} \\
d_{i}^{+} \geq 0, d_{i}^{-} \geq 0 \\
j=1,2, \ldots, n ; i=1,2, \ldots, m
\end{array}\right.
\end{gathered}
$$


In a mathematical expression, total $n$ priority levels and $m$ objectives are listed in the utility function, where $d^{+}$and $d^{-}$represent the positive and negative deviational variables, respectively. $P_{j}$ represents the priority level of the $j$ th objectives. The deviational variables reveal the deviational distance to the objectives. Generally, since the decision value is impossible to exceed, and cannot exceed the target at one time, the formula $d^{+} \times d^{-}=0$ is always true [45]. Shorter distances from the deviational variables to the targets denote better optimization effects. In order to examine the relative importance of the objectives in the same priority levels, $w$, as the preferential weight, is used and can be determined by the multi-criteria decision making (MCDM). The hard constraints are placed in the first priority level to define the solution space boundary. The soft constraints are arranged in the other lower levels to satisfy the DM's will, and the priority of the upper level objective is considerably more important than those in the inferior levels. Finally, the optimized solution is obtained by comparing the deviational values in the corresponding ranks. Although incommensurability does not occur in different priority levels, normalization techniques, such as Euclidean normalization [46], the zero-one normalization [47], and the percentage normalization [43], are still required to judge the optimization effects of different objectives in the same priority level.

\subsubsection{Development of Generalized Goal Programming Optimization Model}

A generalized GPM-based optimization model is proposed in this study to fit the decision-making process, and the generalized expression is shown as below:

$$
\begin{aligned}
& \min z=P_{1}\left(d_{1}^{-}+d_{1}^{+}\right)+P_{2}\left(d_{2}^{-}+d_{2}^{+}\right)+P_{3}\left(d_{3}^{-}+d_{3}^{+}\right) \\
& \text {s.t. }\left\{\begin{array}{l}
\sum_{j=1}^{n} \sum_{i=1}^{m} c_{j}^{i}-d_{1}^{+}+d_{1}^{-}=C \\
\sum_{k=1}^{q} e_{k}-d_{2}^{+}+d_{2}^{-}=E \\
\sum_{j=1}^{n} \sum_{i=1}^{m} c e_{j}^{i}-d_{3}^{+}+d_{3}^{-}=C E \\
e_{k} \geq 0, c_{j}^{i} \geq 0, c e_{j}^{i} \geq 0 \\
j=1,2, \ldots, n ; i=1,2, \ldots, m ; k=1,2, \ldots, q
\end{array}\right.
\end{aligned}
$$

In this mathematical expression, three objectives are employed to describe the DMs' preferences in three priority levels. The objectives are represented by the summation of the itemized data. As a result, the $j$ and $i$ are used to signify the architectural components involved in the design alternatives and the different layers in these components, respectively. $C$ represents the objective of the investment budget, $c$ represents the comprehensive unit price (CUP) of each material, and $E$ represents the energy consumption limit. In the energy consumption objective, the itemized energy consumption index $e_{k}$ (in which $k$ means the sub-item energy consumption index such as heating, cooling, and lighting) can be added into the mathematical expression based on the DMs' preferences. The CE represents the limitation of the carbon dioxide emissions, and it is measured by the Carbon Emission Factor (CEF) denoted by ce. Meanwhile, due to the subjectivity in the objective determination process, the preset objectives may not be located in the solution space. A solution is proposed to provide the DMs with a reasonable advice to determine the optimization objective value. The relationship between the theoretical solution space and the actual solution space is presented in Figure 1. In this figure, the boundary of the theoretical solution space is determined by the minimized and maximized values of each single objective. Actually, solutions in the theoretical solution space do not exist in some cases, because the objectives are contradictory. For example, achieving minimized $C$ (the objective of the investment budget) and minimized $E$ (energy consumption limit) in a design scheme is nearly impossible, because material usage has opposite effects on the $C$ and $E$. Therefore, the theoretical solution space is a critical reference to the DMs' initial objective setting. As for the satisfactory solution, although it does not rigorously satisfy 
each constraint, it can still ensure an equivalent level to the preset single objective. Comparing with the non-dominated solutions on the Pareto frontier, the satisfactory solution is preferred to express the DMs' preferences based on the re-definition of the actual solution space. Moreover, it is evident that no non-dominated solution is effective in most cases, particularly when the number of the soft constraints is more than one. Therefore, the GPM possesses large potential in building energy efficiency optimization.

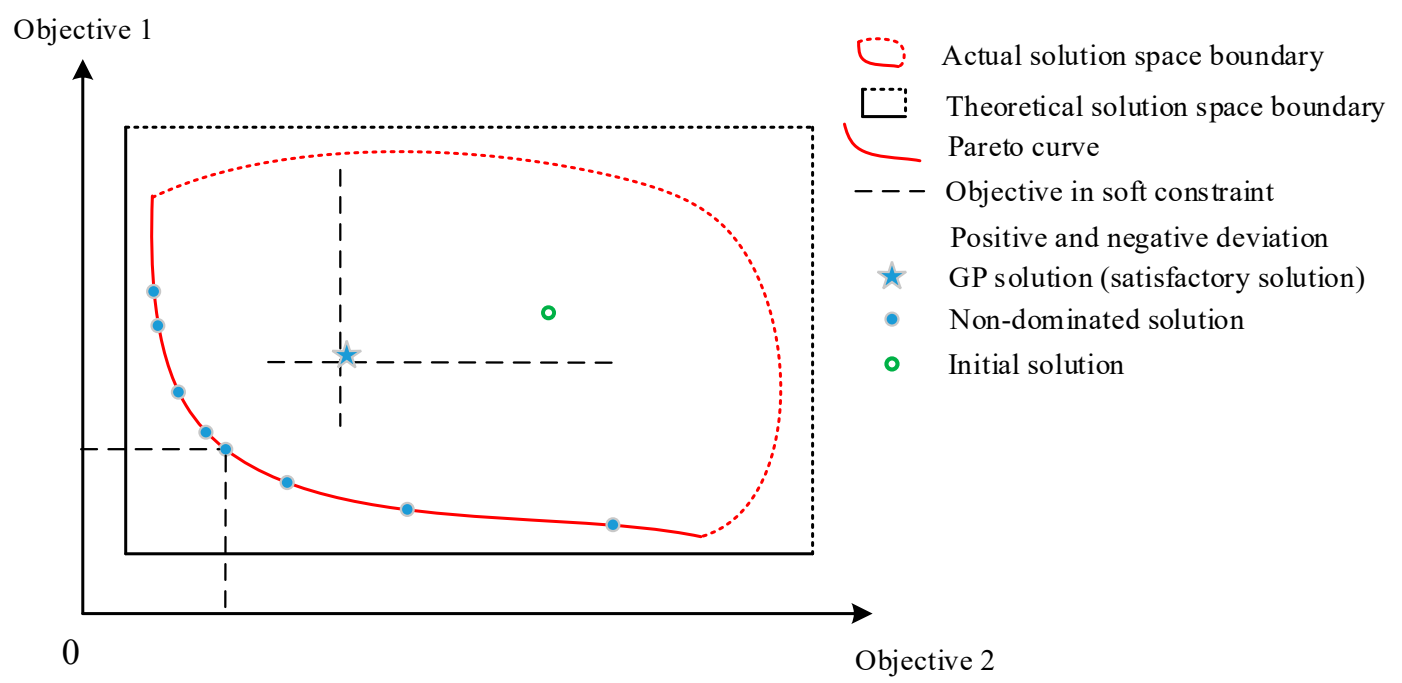

Figure 1. Relationship between the theoretical solution space and the actual solution space.

\subsection{Optimization Procedure}

Since a large number of design parameter combinations are considered in the optimization model, long execution time is expected in the solving procedure due to the approximately 3 to $5 \mathrm{~min}$ of EnergyPlus ${ }^{\mathrm{TM}}$ execution time for each design scenario. In a worst-case scenario, the total optimization time can reach over hundreds of years [15,22]. Therefore, an overall research scheme driven by Python code is proposed in this study to speed up the entire solving procedure, as presented in Figure 2, which contains three main modules: optimization modeling, the GPM solution, and the GA generation loop. As shown in Figure 2, there are three processes connecting these three modules by delivering necessary information. The functions of the arrows 1,2 , and 3 are explained in this figure. Optimization modeling is responsible for providing the GPM for the GA iteration. The GPM solution is the process to calculate the design scheme performance. When the stop condition (preset deviation thresholds) is met, the iteration ends and outputs the satisfactory solution. 


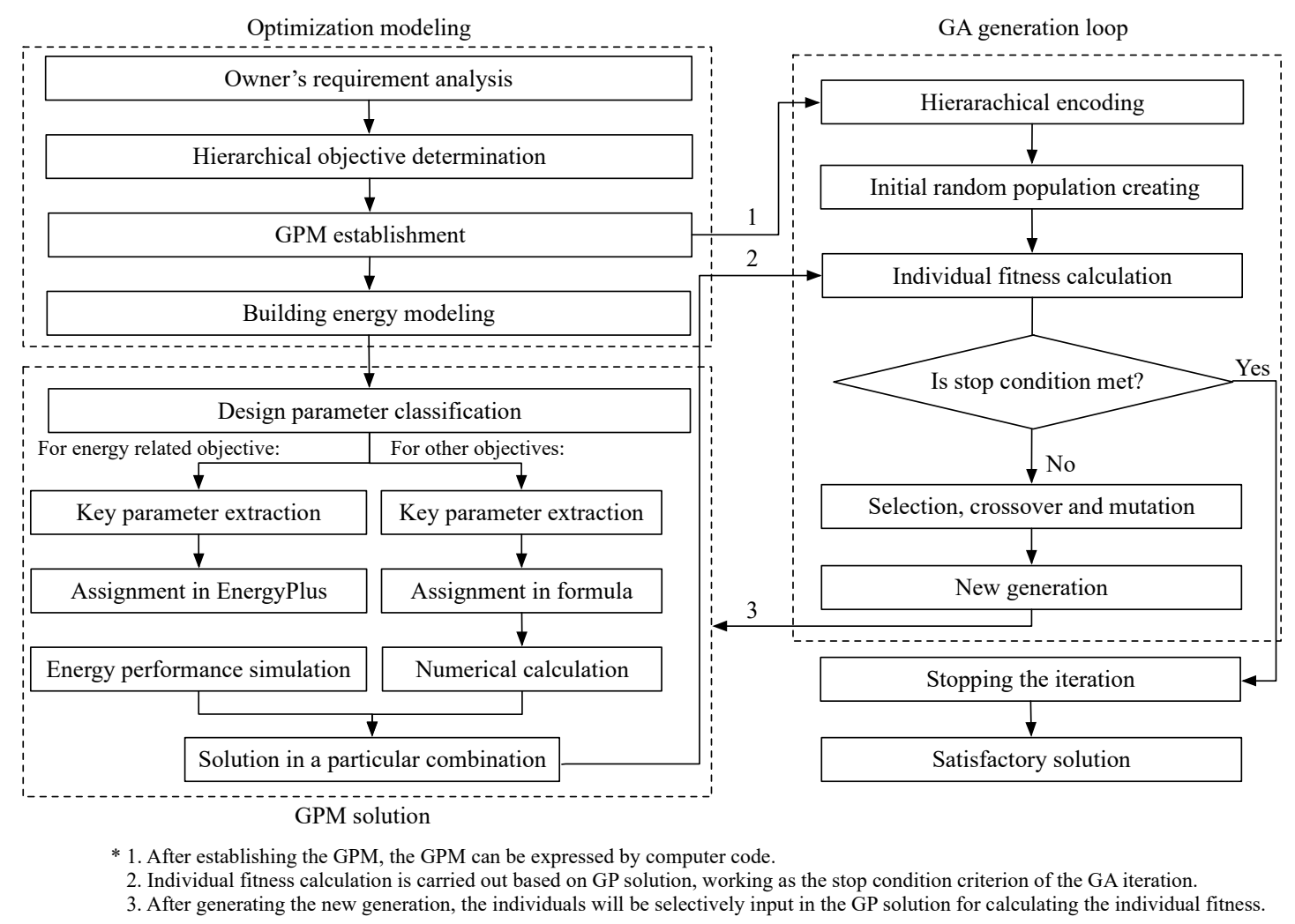

Figure 2. Overall research scheme for the GP-based building energy efficiency design optimization.

\subsubsection{Optimization Modeling}

Optimization modeling is the preliminary work in this study, and it is performed according to the DM's design requirements. The owner or stakeholder's requirements are classified according to different levels of influences by the specific indicators such as restricted investment, environmental benefits, and limited construction period. By means of collecting information from interviews and contractual provisions, the design requirements for a certain construction project are easily grasped by the designer, who is responsible for understanding and satisfying the stakeholder's targets. Moreover, the utilities of these requirements are not equal. For example, housing developers tend to strive for maximized economic benefit, while government projects are designated to be green building models; as a result, the influential factors, which the stakeholders prefer to give priority to, determine the overall project benefits including the energy performance during the entire life cycle of the building. On the other hand, in some cases, the importance of these criteria is not expressed by weightings but by hierarchical objectives, which are described by natural language. A common expression is "improving energy consumption performance as much as possible under a restricted investment premise". In this context, investment is the first level objective, and energy consumption performance is the lower level objective. Thus, the hierarchical objective can be determined according to the stakeholders' preferences. Subsequently, a corresponding GPM is established to present the objectives above, and both hard and soft constraints can exist. Several objectives existing in the same level is also permitted for fitting a wide range of applications. Finally, a building energy model is developed in the Google Sketchup and the plug-in OpenStudio ${ }^{\circledR}$ [48] to generate the EnergyPlus $^{\mathrm{TM}}$ input file (.idf). Moreover, the thermal property assignment for the developed energy model is carried out in EnergyPlus ${ }^{\mathrm{TM}}$ classes. The primary information in the energy model includes basic simulation settings, construction, material, electric equipment, occupant behavior and schedule. These factors are all preset to conform to the operation conditions for each thermal zone. 


\subsubsection{GPM Solution}

The next module, GPM solution, is included to acquire the solution for each combination of design parameters, such as the material, thickness, and size of the components, in the GPM. This process is divided into two parts to handle the two different types of constraint forms.

The first form is represented by several evaluation indexes, which can build strong relationships with the input design parameter combinations. However, such relationships are difficult to express in mathematical expressions due to their complexity. In this study, the energy-related objective is measured by the sum of the values of the sub-item energy consumption indexes. Although a remarkable connection has been proven in the literature between the design parameter selection and variation of these indexes [49,50], the thermodynamic interaction process is difficult to integrate into a certain mathematical expression without any help of approximate treatment. As a result, EnergyPlus ${ }^{\mathrm{TM}}$ is employed as a black box function to reveal the energy consumption performance within a group of specific design parameters for the energy-related objective. Consequently, EnergyPlus ${ }^{\mathrm{TM}}$ is required to participate in the process of searching for solution for each design scheme.

The second form is expressed by linear equations, where these equations are usually used to measure the investment in the construction phase, the carbon emissions of materials, and the duration caused by various construction technologies and usage. At the end, it is important to highlight that these two forms are interchangeable. For example, previous studies have demonstrated that surrogate models, such as the linear regression and polynomial models are also considered as effective methods to reveal building energy consumption performance laws [49,50]. Meanwhile, the investment budget can be calculated by calling quantity take-off and estimating software as the substitution of simple summation [51]. In spite of the relatively high accuracy, the complex operation and exponentially increased time consumption constitute the main obstacles in realizing the objectives. Considering the limited application ranges of the current surrogate models, the simulation engine is used to describe the energy-related objective.

\subsubsection{GA Generation Loop}

As mentioned previously, the "Trial-and-Error" approach is unacceptable for stakeholders because of the time limitation. It is crucial to automate this task to create an intelligent form to find good design solutions instead of exploring all of these alternatives [23]. Therefore, the last module proposes a GA-based optimizing workflow to significantly improve the optimization efficiency. In this module, the GPM solution acts as the input for the GA generation loop, which is mainly responsible for acquiring the final satisfactory solution. The GA is a widely used evolutionary algorithm based on the principle of natural selection and genetic mechanism [52], and it considers the population as a solution space, with each solution in the space regarded as an individual. Essentially, the objective of the GA optimization process is to search for the individuals with strong environmental adaptability (high fitness), which is determined by the individual chromosome sequence. Meanwhile, the environmental adaptability is represented by the fitness function, which is the optimization objective. Through multiple iterations in the optimization process, individuals with low fitness are diminished, and individuals with relatively high fitness are filtrated as the potential optimal solutions. In this study, each solution and corresponding design parameters are considered to be the individual and the chromosomes in the GA hierarchical encoding, respectively. For example, "thermal properties of various materials and material thickness take effects on the building energy consumption performance", in which the former two parameters work as the chromosomes and the latter parameter denotes the individual. Moreover, the genes represent the building components, such as wall, roof, and window. The general mathematical expressions of the individuals and genes are two vectors just as $\left(d_{1}, d_{2}, \ldots, d_{k}\right)$ and $\left(x_{1}, x_{2}, \ldots, x_{n}\right)$. An initial random population is selected as the parents. The fitness of the parents is calculated subsequently based on the GPM requirements, which regulates the progressive decrease of the importance levels in 
the individual vector. Thus, a lower value with high priority represents a higher individual fitness. If individuals that satisfy the requirement of deviational fluctuation in the current generation are present, the GA will stop and will output the satisfactory solution. On the contrary, if current generation does not meet the stakeholder's requirements, then the operation, covering selection, crossover, and mutation, will be implemented to have new generations search for individuals with better fitness. The calculation iteration stops when the satisfactory solution appears in this circumstance. Specifically, the steps connected by dotted arrows shown in Figure 2 continuously work until the iteration stops. Ultimately, the output of this optimizing process is a satisfactory solution for the DMs.

\section{Case Study}

\subsection{Case Introduction}

A five-story office building located inside the campus of Dalian University of Technology, Liaoning Province, China, was selected for the case study. The building is located in an area with the typical temperate monsoon climate. The energy model of this complex office building established in Google Sketchup is shown in Figure 3. The building total area is $10,445 \mathrm{~m}^{2}$, and the internal space is divided into different types of office spaces such as professors' offices, students' offices, meeting rooms, laboratories, corridors, and file rooms. Each type of office space (or room) has its own energy consumption pattern, and Table 1 lists the detailed classification standards, acquired by site survey. In this case, the energy consumption patterns in Table 1, including occupant behavior, internal loads, equipment, are input in the EnergyPlus model as model parameters in standard parametrized form. In view of the pre-determined purpose and construction plant of a newly designed building, only envelope-related parameters are considered as the tuning variables in the optimization process. The thermal bridge is neglected in this case, and the case selects the ideal air conditioner system by default. In addition, although many scenarios are not considered in this case, the architectural appearance is flexible based on the Sketch Up modeling and EnergyPlus simulation scheme, especially because the EnergyPlus strictly follows a parametrized three-dimensional coordinate input module. The space size, window size, space shape, etc., can be easily replaced in the optimization model to meet various design requirements, such as greater light comfort and architectural aesthetic, by only numerical input.

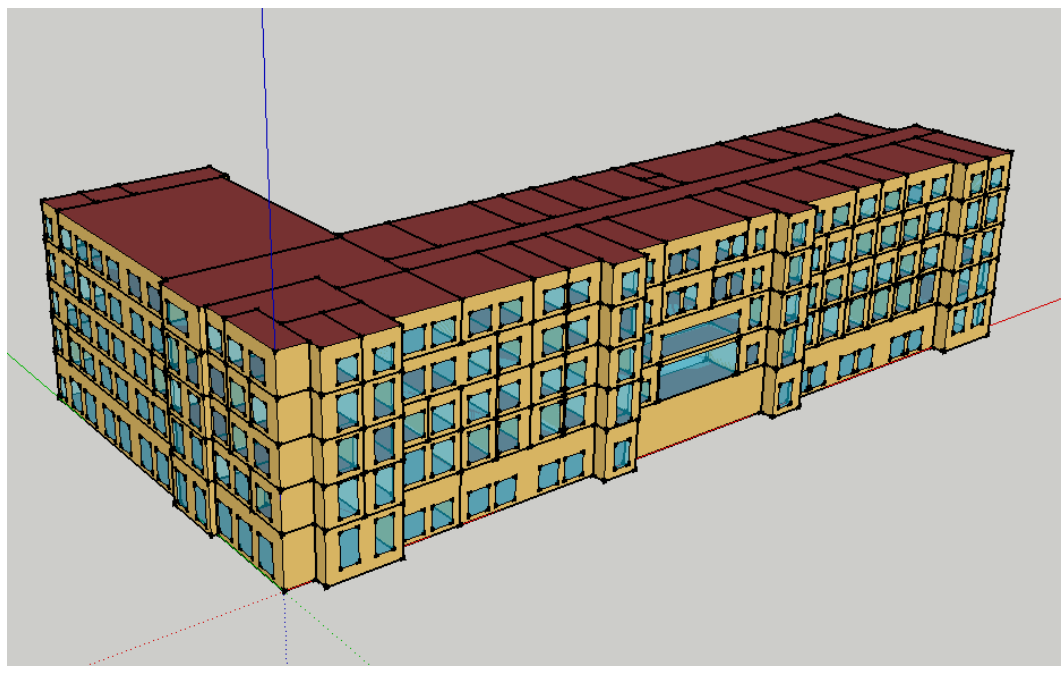

Figure 3. Building energy model of the case study. 
Table 1. Energy consumption patterns in different office spaces (rooms).

\begin{tabular}{cccccc}
\hline & $\begin{array}{c}\text { People } \\
\text { Density }\end{array}$ & $\begin{array}{c}\text { Equipment } \\
\text { Density }\end{array}$ & $\begin{array}{c}\text { Usage } \\
\text { Duration }\end{array}$ & $\begin{array}{c}\text { Heating } \\
\text { Room }\end{array}$ & $\begin{array}{c}\text { Cooling } \\
\text { Room }\end{array}$ \\
\hline Professor Office & Medium & Medium & Medium & Yes & Yes \\
Student Office & Large & Large & Long & Yes & Yes \\
Laboratory & Low & Low & Medium & Yes & Yes \\
Meeting Room & Large & Low & Short & Yes & Yes \\
Corridor & - & - & - & No & No \\
File Room & Low & Low & Short & Yes & Yes \\
\hline
\end{tabular}

This case study is dedicated to implement the optimization model proposed in this study by adjusting the building envelope design considering various energy consumption patterns. Five building components are taken into consideration: the exterior wall, roof, exterior slab carpet, ceiling/floor, and window, which are, respectively, denoted by $v_{1}$ to $v_{5}$ in sequence. The components are divided into a maximum of three layers according to their construction requirements. Layer 1 represents the main components that make up the structure for stability, such as concrete, bricks, or building blocks; Layer 2 is applied in the surfaces exposed to sunlight for necessary thermal performance design; and Layer 3 is responsible for leveling and aesthetics. For example, $v_{1}^{1}$ represents the material for Layer 1 in the exterior wall. The thermal property parameters, the CUP and the CEF, of the replaceable materials are shown in Tables 2 and 3. The design parameters derived from the Thermal Design Code of Civil Buildings (GB 50176-2016) [53]. The CUP is calculated according to the code of bills of quantities and valuation for construction works (GB 505002013) [54], and the CEF is taken from the online statistics [55]. In view of the restrictions such as land use, lighting, and ventilation requirement, the adjustable design parameters, including orientation, architectural appearance, and size of the windows, are not completely involved in this case.

Table 2. Calculating parameters of the building envelope $\left(v_{1}-v_{4}\right)$.

\begin{tabular}{|c|c|c|c|c|c|c|c|}
\hline & No. & $\begin{array}{l}\text { Density } \\
\left(\mathrm{kg} / \mathrm{m}^{3}\right)\end{array}$ & $\begin{array}{l}\text { Conductivity } \\
(\mathrm{W} / \mathrm{m} \cdot \mathrm{K})\end{array}$ & $\begin{array}{c}\text { Specific Heat } \\
(\mathrm{J} / \mathrm{kg} \cdot \mathrm{K})\end{array}$ & $\begin{array}{l}\text { Thickness } \\
\text { (m) }\end{array}$ & $\begin{array}{c}\text { CUP } \\
\left(\mathrm{CNY} / \mathrm{m}^{3}\right)\end{array}$ & $\begin{array}{c}\text { CEF } \\
\left(\mathrm{kg} / \mathrm{m}^{3}\right)\end{array}$ \\
\hline \multirow{7}{*}{$v_{1}^{1}$} & 1 & 800 & 0.54 & 1050 & \multirow{7}{*}[0.12,0.37]{} & 355.85 & 321.99 \\
\hline & 2 & 1400 & 0.58 & 1050 & & 290.94 & 488.79 \\
\hline & 3 & 1800 & 0.87 & 1050 & & 278.11 & 273 \\
\hline & 4 & 2300 & 1.453 & 1050 & & 375.95 & 301.97 \\
\hline & 5 & 1280 & 1.12 & 1050 & & 224.64 & 146 \\
\hline & 6 & 700 & 0.18 & 1050 & & 423.73 & 230 \\
\hline & 7 & 2350 & 1.579 & 874 & & 572 & 399.9 \\
\hline \multirow{5}{*}{$v_{1}^{2}$} & 1 & 25 & 0.03 & 5350 & \multirow{5}{*}[0.02,0.1]{} & 767.28 & 43.75 \\
\hline & 2 & 18 & 0.041 & 2410 & & 411.17 & 27.5 \\
\hline & 3 & 120 & 0.045 & 750 & & 860.8 & 19.75 \\
\hline & 4 & 30 & 0.042 & 1380 & & 889.9 & 154 \\
\hline & 5 & 30 & 0.033 & 1380 & & 910.58 & 174 \\
\hline$v_{1}^{3}$ & 1 & 1800 & 0.93 & 1050 & {$[0.01,0.05]$} & 937.37 & 377 \\
\hline \multirow{2}{*}{$v_{2}^{1}$} & 1 & 2300 & 1.453 & 1050 & \multirow{2}{*}[0.1,0.25]{} & 379.95 & 301.97 \\
\hline & 2 & 2350 & 1.579 & 874 & & 591.13 & 399.9 \\
\hline \multirow{4}{*}{$v_{2}^{2}$} & 1 & 25 & 0.03 & 5350 & \multirow{4}{*}[0.02,0.1]{} & 589.62 & 43.75 \\
\hline & 2 & 18 & 0.041 & 2410 & & 376.62 & 27.5 \\
\hline & 3 & 120 & 0.045 & 750 & & 484 & 102.4 \\
\hline & 4 & 30 & 0.42 & 1380 & & 587.15 & 154 \\
\hline \multirow{2}{*}{$v_{2}^{3}$} & 1 & 1800 & 0.93 & 1050 & \multirow{2}{*}[0.01,0.05]{} & 937.37 & 377 \\
\hline & 2 & 2100 & 1.28 & 1050 & & 728.4 & 239.19 \\
\hline
\end{tabular}


Table 2. Cont.

\begin{tabular}{|c|c|c|c|c|c|c|c|}
\hline & No. & $\begin{array}{l}\text { Density } \\
\left(\mathrm{kg} / \mathrm{m}^{3}\right)\end{array}$ & $\begin{array}{l}\text { Conductivity } \\
(\mathrm{W} / \mathrm{m} \cdot \mathrm{K})\end{array}$ & $\begin{array}{l}\text { Specific Heat } \\
(\mathrm{J} / \mathrm{kg} \cdot \mathrm{K})\end{array}$ & $\begin{array}{c}\text { Thickness } \\
\text { (m) }\end{array}$ & $\begin{array}{c}\text { CUP } \\
\left(\mathrm{CNY} / \mathrm{m}^{3}\right)\end{array}$ & $\begin{array}{c}\text { CEF } \\
\left(\mathrm{kg} / \mathrm{m}^{3}\right)\end{array}$ \\
\hline \multirow{2}{*}{$v_{3}^{1}$} & 1 & 2300 & 1.453 & 1050 & \multirow{2}{*}[0.08,0.25]{} & 379.95 & 301.97 \\
\hline & 2 & 2350 & 1.579 & 874 & & 591.13 & 399.9 \\
\hline \multirow{5}{*}{$v_{3}^{2}$} & 1 & 25 & 0.03 & 5350 & \multirow{5}{*}[0.02,0.1]{} & 767.28 & 43.75 \\
\hline & 2 & 18 & 0.041 & 2410 & & 511.17 & 27.5 \\
\hline & 3 & 120 & 0.045 & 750 & & 860.8 & 102.4 \\
\hline & 4 & 30 & 0.042 & 1380 & & 516.19 & 154 \\
\hline & 5 & 30 & 0.033 & 1380 & & 910.58 & 174 \\
\hline \multirow{2}{*}{$v_{3}^{3}$} & 1 & 1800 & 0.93 & 1050 & \multirow{2}{*}[0.01,0.05]{} & 937.37 & 377 \\
\hline & 2 & 2100 & 1.28 & 1050 & & 728.4 & 239.19 \\
\hline \multirow{2}{*}{$v_{4}^{1}$} & 1 & 2300 & 1.453 & 1050 & \multirow{2}{*}[0.08,0.15]{} & 379.95 & 301.97 \\
\hline & 2 & 2350 & 1.579 & 874 & & 591.13 & 399.9 \\
\hline \multirow{2}{*}{$v_{4}^{2}$} & 1 & 1800 & 0.93 & 1050 & \multirow{2}{*}[0.01,0.05]{} & 937.37 & 377 \\
\hline & 2 & 2100 & 1.28 & 1050 & & 728.4 & 239.19 \\
\hline
\end{tabular}

Table 3. Calculating parameters of the building envelope $\left(v_{5}\right)$.

\begin{tabular}{ccccccc}
\hline & No. & $\begin{array}{c}\text { U-Factor } \\
\left(\mathbf{W} / \mathbf{m}^{\mathbf{2}} \cdot \mathbf{K}\right)\end{array}$ & SHGC & $\begin{array}{c}\text { Thickness } \\
\mathbf{( m )}\end{array}$ & $\begin{array}{c}\text { CUP } \\
\left(\mathbf{C N Y} / \mathbf{m}^{\mathbf{2}}\right)\end{array}$ & $\begin{array}{c}\text { CEF } \\
\left(\mathbf{k g} / \mathbf{m}^{\mathbf{2}}\right)\end{array}$ \\
\hline & 1 & 5.818 & 0.8 & 0.0058 & 79.81 & 18.87 \\
& 2 & 5.604 & 0.76 & 0.012 & 126.56 & 34.98 \\
$v_{5}^{1}$ & 3 & 5.58 & 0.75 & 0.010 & 221.06 & 29.58 \\
& 4 & 3.109 & 0.72 & 0.018 & 126.56 & 34.98 \\
& 5 & 2.835 & 0.72 & 0.021 & 143.06 & 34.98 \\
& 6 & 2.7 & 0.72 & 0.024 & 148.06 & 34.98 \\
& 7 & 2.084 & 0.68 & 0.021 & 252.06 & 37.41 \\
\hline
\end{tabular}

* Solar heat gain coefficient.

\subsection{Optimization with Five Scenarios}

The GP-based optimization model is established in five different scenarios, prepared based on various preference descriptions. Through the settings of these five scenarios, the case will demonstrate how the GP-based optimization model works and will validate the effectiveness and flexibility of the GPM in the building energy efficiency optimization. The model expression for these five scenarios are listed in Table 4. Scenario 1 gives the basic expression, and the other four scenarios can be considered as the variants of Scenario 1. Detailed information of the five scenarios will be introduced subsequently.

Similar to the generalized GP optimization model established in Section 3.1.2, a total of three objectives $(C, E, C E)$ are referred in the Scenario 1 model. The construction investment $C$ is in the first priority level, and the environmental index $C E$ is the least important priority level. All these objectives are regulated to be approached from the positive direction. In a linguistic expression, the DMs prefer that the actual values of investment cost, energy consumption performance, and carbon dioxide emissions will not exceed the pre-defined objective values as far as it is possible. $x$ and $y$ represent the CUP and CEF of the selected materials, respectively. $\gamma$ is the material's rate of waste, which is defined as $3 \% . \beta$ and $\alpha$ are used to indicate the material consumptions, where $\beta$ is the material utility area and $\alpha$ is the material thickness in a specific layer. The thickness of the window is not included because the related calculation is only based on the unit area. $E_{\text {cooling }}$ (annual cooling load in the entire building) and $E_{\text {heating }}$ (annual heating load in the entire building) are two itemized indicators for measuring the building energy consumption performance.

In Scenario 1, C, E and $C E$ are defined as three objectives in three priority levels. The objective $C$ is the most important, and the $C E$ is the least important. Due to the meanings of the $C, E$, and $C E$, the DMs tend to prefer these values smaller than the certain objective 
values. Therefore, the positive deviations in each optimization objectives are permitted for applying the satisfactory solution. This model is also the standard expression of this case study. These three constraints are all soft constraints coupled with corresponding positive deviational variables, and they are regarded as a type of basic demands of the DMs.

Scenario 2 is discussed as a slightly modified model compared with Scenario 1 . In the first priority level constraint, both positive and negative deviational variables are allowed, which indicates that the first objective $C$ can be approximated from two directions. In this scenario, a less constrained case compared with Scenario 1 is discussed to explore whether it can obtain more precise optimal results.

Scenario 3 emphasizes environmental and public benefits. Therefore, the objectives are realigned according to these new concerns. The Objectives $E$ and $C E$ are arranged at the first two priority levels in all these objectives, and the Objective $C$ is the least important. Like Scenario 1, only positive deviations are allowed in the satisfactory solution.

Given the objectives with similar degrees of concerns for the DMs, different objectives existing in the same priority level is common. To present how the GPM works in such a scenario, Scenario 4 sets two objectives ( $E_{\text {heating }}$ and $\left.E_{\text {cooling }}\right)$ in the same priority level, which indicates they can be quantified by the same order of magnitude. Different weights are also assigned based on the relative importance. In this case, the relative importance between the $E_{\text {heating }}$ and $E_{\text {cooling }}$ are defined as 1:1.

Scenario 5 takes hard constraints or the compelling objectives into account. Some conditions that must be met are expressed without deviational variables. In this scenario, the first level constraint $C$ is set as the rigorous prerequisites in the GPM. Therefore, the satisfactory solution only exists in the Objectives $E$ and $C E$.

Generally, the only difference between Scenario 1 and 2 is that both positive and negative deviations can appear in the first priority level in Scenario 2. It indicates that the DMs are intended to reach the objective without restricted approach directions. Scenario 3 focuses on the environmental benefits and, therefore, the Objectives $E$ and $C E$ are arranged in the higher priorities. Scenario 4 sets more than one objective $\left(E_{\text {cooling }}\right.$ and $\left.E_{\text {heating }}\right)$ in the same priority level, and $E_{\text {cooling }}$ and $E_{\text {heating }}$ are weighted depending on the relative importance. Scenario 5 adds the hard constraints into the format. The hard constraint should be rigorously followed during the optimization process; thus, the hard constraint is situated in the first priority level of the GPM. 
Table 4. Model expression for the five scenarios in the case study.

\begin{tabular}{|c|c|c|c|c|c|c|}
\hline & & Scenario 1 & Scenario 2 & Scenario 3 & Scenario 4 & Scenario 5 \\
\hline $\begin{array}{c}\text { Model } \\
\text { Expression }\end{array}$ & $P_{3} d_{3}^{+}$s.t. & $\begin{array}{l}\min z=P_{1} d_{1}^{+}+P_{2} d_{2}^{+}+ \\
\left\{\begin{array}{l}\sum_{j=1}^{n} \sum_{i=1}^{m}(1+\gamma) \beta_{j} \alpha_{j}^{i} x_{j}^{i}-d_{1}^{+}=C \\
E_{\text {Cooling }}+E_{\text {Heating }}-d_{2}^{+}=E \\
\sum_{j=1}^{n} \sum_{i=1}^{m}(1+\gamma) \beta_{j} \alpha_{j}^{i} y_{j}^{i}-d_{3}^{+}=C E \\
a_{j}^{i} \geq 0, x_{j}^{i} \geq 0, y_{j}^{i} \geq 0 \\
d^{+} \geq 0 \\
j=1,2, \ldots, n ; i=1,2, \ldots, m\end{array}\right.\end{array}$ & $\begin{array}{c}\min z=P_{1}\left(d_{1}^{-}-d_{1}^{+}\right)+P_{2} d_{2}^{+}+ \\
P_{3} d_{3}^{+} \text {s.t. }\left\{\begin{array}{l}\sum_{j=1}^{n} \sum_{i=1}^{m}(1+\gamma) \beta_{j} \alpha_{j}^{i} x_{j}^{i}+d_{1}^{-}-d_{1}^{+}=C \\
E_{\text {Cooling }}+E_{\text {Heating }}-d_{2}^{+}=E \\
\sum_{j=1}^{n} \sum_{i=1}^{m}(1+\gamma) \beta_{j} \alpha_{j}^{i} y_{j}^{i}-d_{3}^{+}=C E \\
a_{j}^{i} \geq 0, \beta_{j} \geq 0, x_{j}^{i} \geq 0, y_{j}^{i} \geq 0 \\
d^{+} \geq 0, d^{-} \geq 0 \\
j=1,2, \ldots, n ; i=1,2, \ldots, m\end{array}\right.\end{array}$ & $\begin{array}{c}\operatorname{minz}=P_{1} d_{1}^{+}+P_{2} d_{2}^{+}+ \\
P_{3} d_{3}^{+} \text {s.t. }\left\{\begin{array}{l}E_{\text {Cooling }}+E_{\text {Heating }}-d_{1}^{+}=E \\
\sum_{j=1}^{n} \sum_{i=1}^{m}(1+\gamma) \beta_{j} \alpha_{j}^{i} y_{j}^{i}-d_{2}^{+}=C E \\
\sum_{j=1}^{n} \sum_{i=1}^{m}(1+\gamma) \beta_{j} \alpha_{j}^{i} x_{j}^{i}-d_{3}^{+}=C \\
a_{j}^{i} \geq 0, x_{j}^{i} \geq 0, y_{j}^{i} \geq 0 \\
d^{+} \geq 0 \\
j=1,2, \ldots, n ; i=1,2, \ldots, m\end{array}\right.\end{array}$ & $\begin{array}{c}\min z= \\
P_{3} d_{4}^{+} \text {s.t.t. } \\
\qquad \begin{array}{l}\sum_{1} d_{1}^{+}+P_{2}\left(w_{22} d_{2}^{+}+w_{32} d_{3}^{+}\right)+ \\
\sum_{j=1}^{m} \sum_{i=1}^{m}(1+\gamma) \beta_{j} \alpha_{j}^{i} x_{j}^{i}-d_{1}^{+}=C \\
E_{\text {Heating }}-d_{2}^{+}=E_{h} \\
E_{\text {Cooling }}-d_{3}^{+}=E_{c} \\
\sum_{j=1}^{n} \sum_{i=1}^{m}(1+\gamma) \beta_{j} \alpha_{j}^{i} y_{j}^{i}-d_{4}^{+}=C E \\
a_{j}^{i} \geq 0, x_{j}^{i} \geq 0, y_{j}^{i} \geq 0, d^{+} \geq 0 \\
j=1,2, \ldots, n ; i=1,2, \ldots, m\end{array}\end{array}$ & $\begin{array}{c}\min z=P_{1} d_{1}^{+}+ \\
P_{2} d_{2}^{+} \text {s.t. }\left\{\begin{array}{l}\sum_{j=1}^{n} \sum_{i=1}^{m}(1+\gamma) \beta_{j} \alpha_{j}^{i} x_{j}^{i} \leq C \\
E_{\text {Cooling }}+E_{\text {Heating }}-d_{1}^{+}=E \\
\sum_{j=1}^{n} \sum_{i=1}^{m}(1+\gamma) \beta_{j} \alpha_{j}^{i} y_{j}^{i}-d_{2}^{+}=C E \\
a_{j}^{i} \geq 0, x_{j}^{i} \geq 0, y_{j}^{i} \geq 0 \\
d^{+} \geq 0 \\
j=1,2, \ldots, n ; i=1,2, \ldots, m\end{array}\right.\end{array}$ \\
\hline
\end{tabular}




\subsection{Programming}

\subsubsection{Python Programming Design}

PyCharm platform is developed by Python-based computer code to integrate the entire optimization process of this case study. The code realizes the interaction between EnergyPlus $^{\mathrm{TM}}$ simulation and the GA iterations. It contains two main parts: (1) automatic parameter assignment for the energy model and simulation in EnergyPlus ${ }^{\mathrm{TM}}$; and (2) the GA-based optimization model establishment. The former part is used to generate the GA individuals in an effective and sequential manner. First, design parameters in the EnergyPlus ${ }^{\mathrm{TM}}$ input file are alternated based on the GA individual generation rules. Then, the EnergyPlus ${ }^{\mathrm{TM}}$ is called and driven automatically by the Python code, and the energy consumption evaluation index is output as a part of the individual fitness calculation basis. The latter part is responsible for the GA solution. The new individuals generated in the process are then returned to the EnergyPlus ${ }^{\mathrm{TM}}$ simulation to evaluate their energy performance. Due to the GPM evaluation approach, a specific fitness evaluation standard is pre-defined, which helps the optimization model to meet the expected optimization goals. For example, based on the Scenario 1 basic form, different weights are given to three deviations, respectively, to compare their fitness values. Deviation with high priority is given a higher order of magnitude, and the deviations are separated by the separatrix " 00 ". The initial expression of the individual fitness is presented in Figure 4a. Considering that the overlong single deviation can influence the low priority objectives, the function "round ( )" is applied to restrict the length of the deviations. Simultaneously, in order to ensure the quality of the optimization result, deviations are delivered through a relative deviation form. In addition, for the scenarios considering the convergence direction, the penalty function "punish $=-10$ " is introduced in the unsatisfied items. The revised individual fitness is shown in Figure $4 \mathrm{~b}$.

\begin{tabular}{|ccccc|}
\hline $\begin{array}{l}\text { Deviation of the } \\
\text { highest priority }\end{array}$ & Separatrix & $\begin{array}{c}\text { Deviation of the sec- } \\
\text { ond prionity }\end{array}$ & $\begin{array}{c}\text { Separatrix } \\
\text { d1 }\end{array}$ & $\begin{array}{c}\text { Deviation of the third } \\
\text { priority }\end{array}$ \\
\hline$d_{1}$ & $d_{2}$ & 00 & $d_{3}$ \\
\hline
\end{tabular}

(a)

\begin{tabular}{|ccccc|}
\hline $\begin{array}{l}\text { Deviation of the } \\
\text { highest priority }\end{array}$ & Separatrix & $\begin{array}{c}\text { Deviation of the sec- } \\
\text { ond priority }\end{array}$ & $\begin{array}{c}\text { Separatrix } \\
\text { round }\left(d_{1} / C, 2\right)\end{array}$ & $\begin{array}{c}\text { Deviation of the third } \\
\text { priority }\end{array}$ \\
\hline round & 00 & round $\left(d_{2} / E, 2\right)$ & 00 & round $\left(d_{3} / C E, 2\right)$ \\
\hline
\end{tabular}

(b)

Figure 4. Individual fitness expression of the GA model (a) initial expression (b) revised expression.

\subsubsection{Python Code Basic Settings}

In order to provide a reasonable decision-making support for DMs, the theoretical solution space boundaries are determined in advance by means of numeral calculation and simulation based on the data shown in Tables 2 and 3. The detailed information is introduced in Table 5, where the optimization design objective in Scenarios 1 to 5 is set. Specifically, in Scenario 4, the $E_{\text {heating }}$ is considered twice as important as the same priority objective $E_{\text {cooling }}$ because the annual heating load accounts for a larger share comparing with the annual cooling load in this case study. 
Table 5. Optimization objective settings.

\begin{tabular}{cccc}
\hline \multirow{2}{*}{ Objective (Unit) } & \multicolumn{2}{c}{ Solution Boundary } & \multirow{2}{*}{ Selected Objective Value } \\
\cline { 2 - 3 } & Lower & Upper & \\
\hline$C(\mathrm{CNY})$ & $815,673.9$ & $4,014,919$ & $2,000,000$ \\
$E(\mathrm{GJ})$ & 1243.47 & 2473.68 & $1600(1200$ and 400 in Scenario 4$)$ \\
$E C(\mathrm{~kg})$ & $473,451.9$ & $2,095,093$ & $1,200,000$ \\
\hline
\end{tabular}

\subsection{Results and Discussion}

\subsubsection{Optimization Results for the Five Scenarios}

The Python code runs with GA parameter pre-settings, including a crossover rate of 0.9 , a mutation rate of 0.15 , and an initial population size of 10 . The final convergence condition is five generation iterations of the code running. The GA iteration process and ultimate results in Scenarios 1 to 5 are presented in Table 6. The left part in Table 6 shows the GA iterative convergence process. Fitness values of the best individuals after each GA iteration generation are listed first, and the fitness values are expressed by means of the pre-defined hierarchical objective calculation rules referred to in Figure $4 \mathrm{~b}$. In this case, objectives in the first, second, and third priority levels are given the weightings of 100,000,000, 10,000, and 1 in sequence. For example, in the line chart of Table 6, "3,001,700.02" reveals the optimization solution performance of each objective. Based on the GA fitness expression, deviations between the preset objectives and the first, second, and third priority level objectives are around $[2.5 \%, 3.5 \%),[16.5 \%, 17.5 \%)$, and $[1.5 \%, 2.5 \%)$, respectively. As for the expected values after optimization, for example, only positive deviations are allowed in the Scenario 1. The fitness value " $1,001,500.7$ " can be interpreted as corresponding expected objective values, $[2,010,000,2,030,000)$ for the objective $C$, $[1832,1848)$ for the objective $E,[2,034,000,2,046,000)$ for the objective $E C$. As an intuitive interpretation, three diagrams (a), (b) and (c) are applied to present the hierarchical objective convergence in the first, second, and third priority levels, as shown in Table 6. According to the GPM evaluation rules, it is obvious that higher priority objectives are optimized preferentially, particularly in diagram (a), in which all the deviations descend with the GA iteration process. Meanwhile, deviations of all the first priority level objectives reach a satisfying rank $(<1.5 \%)$. Because hard constraint appears in Scenario 5, all the optimized results are considered as completely satisfying conditions; thus, the deviations are nonexistent. The same convergence calculation rules are also applied in diagrams (b) and (c). Scenarios 2, 4, and 5 show good optimization iteration trend in which all the deviations of the objectives gradually decrease. However, the lower priority objective deviations in scenarios 1 and 3 fluctuate due to the contradiction between objectives. The result accuracy issues are mainly caused by the GPM optimizing rules, and the solution will be discussed in Section 4.4.2. 
Table 6. Optimization results in Scenarios 1 to 5.

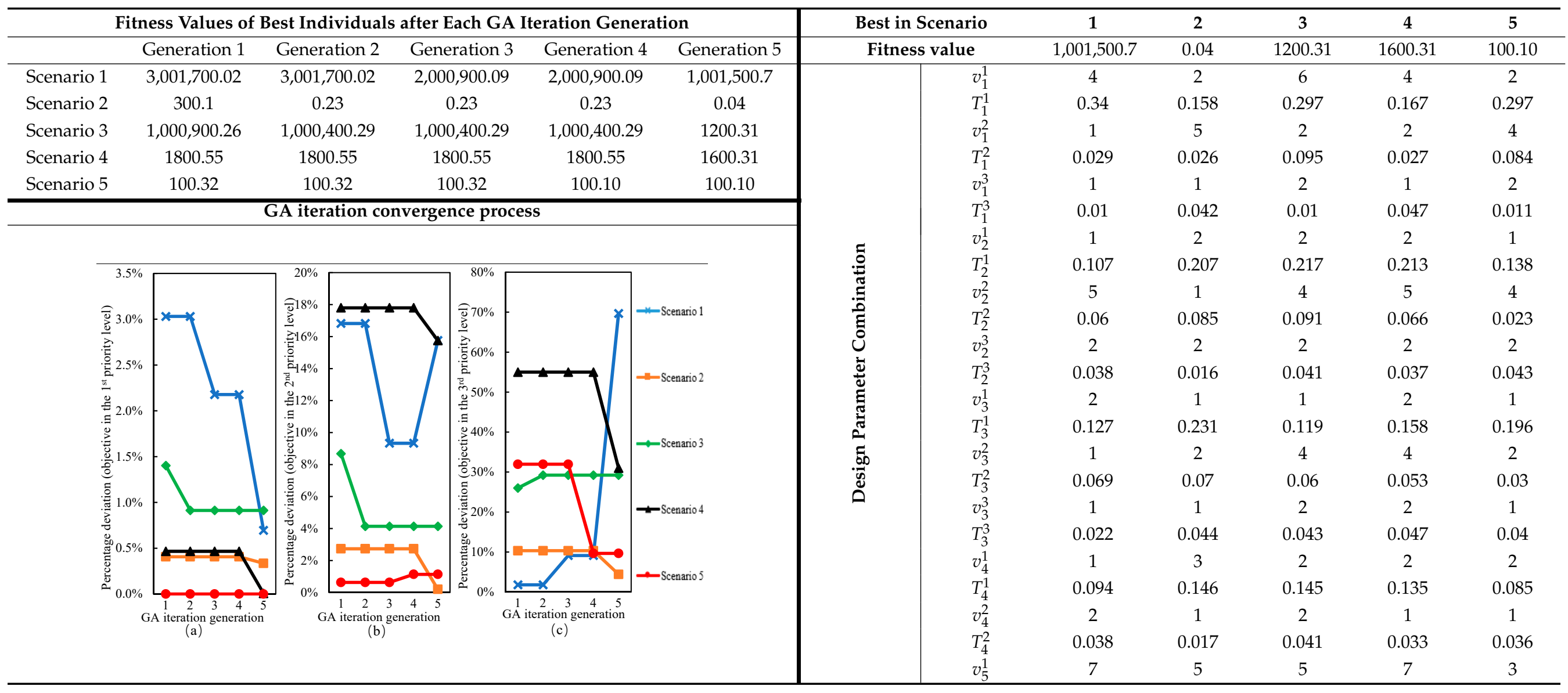


The right part of Table 6 shows the corresponding design parameter values of the best GA individuals. The material selection is represented by the numbers in Tables 2 and 3 (the second column). T represents the thickness of the selected material.

\subsubsection{Discussion}

From the optimization results presented in Table 6, it is clear that the established GP-based optimization method is fully capable of achieving the building energy efficiency optimization. With the help of the GA model, the calculations converge within four days based on the case study settings. Generally, more than 300 design schemes are involved in the GA iterations. Considering the high operational efficiency of the GA, the proposed optimization method can satisfy the project duration requirements of the design phase. In addition, a flexible GPM form is presented in the case study to demonstrate that this model can greatly meet various DMs' initial design requirements. Although the GPM is established to address the hierarchical objective optimization, new issues related to the objective trade-off can arise. Numerically speaking, Scenario 1 cannot be regarded as a successful optimization process because of the approximate deviation of $15 \%$ and $70 \%$ in the second and third priority level objectives. It is still possible to obtain unsatisfying solutions even if much more GA iterations are performed. Essentially, sacrificing lower priority level objectives to support higher priority level objective achievement is emphasized in the GPM approach, which also accords with the rule of building design. If the individual fitness expression of the GA model is not regulated by the method in Figure $4 b$, the GP-based optimization performance must be extremely unstable. There are two ways to solve this problem:

1. Setting strict convergence conditions for each optimization objective in the GA iteration process;

2. Setting a more flexible high priority level objective convergence threshold.

The first solution can be designed according to the maximum acceptable objective deviations from the DMs. The second solution tends to find out the trade-off between objectives. Obviously, in Scenario 1, the GA generations 4 and 5, 1\% deviation reduction for the first priority level objective contributes to $6 \%$ corresponding deviation increment for the second level priority and more than $60 \%$ corresponding deviation increment for the third priority level objectives simultaneously. The similar condition also appears in the Scenario 3 , in which the lower priorities make significant sacrifices to meet high priority objectives. That means various types of optimal results can be provided for the DMs to realize the maximum benefit based on the trade-off among objectives. Generally, secondary screening relying on design requirements can be carried out in the practical projects for avoiding the results in Scenario 1 and 3. Through these improvements, the GP-based optimization method is able to acquire satisfying solution facing different design requirements.

Compared with Scenario 1, the optimization result in the Scenario 2 performs much better, in which the result, respectively, shows [0, 0.5\%), [0, 0.5\%), and [3.5\%, 4.5\%) deviations with the selected objective values. In fact, given the DMs want the Objective $C$ below the expected value and overall optimization performance improves in the Scenario 2, the change for constraint setting is acceptable and even encouraged after looking around.

\section{Conclusions}

In an effort to address the inherent shortcomings of the MOO model, this study proposes a GP-based optimization method. It focused heavily on the decision-making process for DMs support, rather than only on technical evolution in a solid research framework. The GPM introduces a satisfying solution concept into the optimization work, which indicates that the design scheme is not required to rigorously reach the desired objectives. Meanwhile, the GPM answers the main questions regarding how to deal with the objectives with different concerns, and how to approach predefined objective values from specific direction. The optimization is driven by the GA iteration process to improve the computational effectiveness. A case study with five possible design requirements 
is carried out. The optimization results show that the proposed GP-based optimization method can successfully complete the predefined optimization tasks based on different aim expressions. As for the trade-off between objectives, two solutions are proposed to improve the optimization accuracy. The proposed GP-based building energy efficiency optimization method builds a reasonable mathematical expression for those contradictory and preferentially different design objectives. The introduced satisfying solution concept makes the established GP-based optimization method a highly flexible approach in dealing with some specific design requirements, such as clear invested budget and certain design preferences. Generally, the established GPM provides an effective method for building sustainable design. Comparing with the MOO model, the GPM has numerous advantages in flexible model establishment, especially considering various optimization requirements. It is able to better satisfy many specific requirements and efficiently generate feasible energy efficient building designs. This study provides a more flexible and convenient building energy efficiency optimization method for designers and clients to obtain more satisfying design schemes that can fulfill the requirements of the project to the greatest extent possible. It will not only increase the success rate of the projects, but also introduce environmental and economic benefits to the society. Although the method proposed in this paper can be applied to various problems related to the optimal design of building energy efficiency, the case study in this paper only optimizes the building envelope for a specific condition, taking the material cost and carbon emission value into account. Given the parameterized variable input model of the EnergyPlus ${ }^{\mathrm{TM}}$, future research and engineering can use this method for global optimization in terms of the building appearance, geometry, occupant behavior, building equipment, etc.

Author Contributions: Conceptualization, X.L. and S.L.; methodology, X.L. and S.L.; software, X.L. and Y.S.; validation, X.L. and Y.S.; investigation, X.L.; resources, S.L.; data curation, X.L. and Y.S.; writing-original draft preparation, X.L.; writing—review and editing, S.L.; visualization, X.L. and S.L.; supervision, S.L.; funding acquisition, S.L. All authors have read and agreed to the published version of the manuscript.

Funding: This research was funded by the National Natural Science Foundation of China, grant number 71801029; and the Fundamental Research Funds for the Central Universities, grant number DUT20JC18.

Institutional Review Board Statement: Not applicable.

Informed Consent Statement: Not applicable.

Conflicts of Interest: The authors declare no conflict of interest.

\section{References}

1. Alpanda, S.; Peralta-Alva, A. Oil crisis, energy-saving technological change and the stock market crash of 1973-74. Rev. Econ. Dyn. 2010, 13, 824-842. [CrossRef]

2. International Energy Agency (IEA). Key World Energy Statistics 2017; Organisation for Economic Co-operation and Development: Paris, France, 2017.

3. International energy agency (IEA). World Energy Outlook. 2017. Available online: http:/ / www.iea.org (accessed on 8 June 2020).

4. Rebitzer, G. Integrating Life Cycle Costing and Life Cycle Assessment for Managing Costs and Environmental Impacts in Supply Chains. In Cost Management in Supply Chains; Physica: Heidelberg, Germany, 2002; pp. 127-146. [CrossRef]

5. Hong, T.; Taylor-Lange, S.C.; D'Oca, S.; Yan, D.; Corgnati, S.P. Advances in research and applications of energy-related occupant behavior in buildings. Energy Build. 2016, 116, 694-702. [CrossRef]

6. Liu, S.; Meng, X.; Tam, C. Building information modeling based building design optimization for sustainability. Energy Build. 2015, 105, 139-153. [CrossRef]

7. Østergård, T.; Jensen, R.L.; Maagaard, S.E. Early Building Design: Informed decision-making by exploring multidimensional design space using sensitivity analysis. Energy Build. 2017, 142, 8-22. [CrossRef]

8. Wang, C.; Cho, Y.K. Application of as-built data in building retrofit decision making process. Procedia Eng. 2015, 118, 902-908. [CrossRef]

9. Russell-Smith, S.V.; Lepech, M.D.; Fruchter, R.; Meyer, Y.B. Sustainable target value design: Integrating life cycle assessment and target value design to improve building energy and environmental performance. J. Clean. Prod. 2015, 88, 43-51. [CrossRef] 
10. Kaklauskas, A.; Zavadskas, E.K.; Raslanas, S. Multivariant design and multiple criteria analysis of building refurbishments. Energy Build. 2005, 37, 361-372. [CrossRef]

11. Löhnert, G.; Dalkowski, A.; Sutter, W. Integrated Design Process: A Guideline for Sustainable and Solar-Optimised Building Design; International Energy Agency: Paris, France, 2003.

12. Reed, B. The Integrative Design Guide to Green Building: Redefining the Practice of Sustainability; John Wiley \& Sons: Hoboken, NJ, USA, 2009; Volume 43.

13. Shao, Y. A systematic approach to energy efficiency improvements in buildings based on enterprise modeling method. In Proceedings of the SB13 Munich-Implementing Sustainability Changes, Munich, Germany, 24-26 April 2013; pp. 1283-1290.

14. Antipova, E.; Boer, D.; Guillén-Gosálbez, G.; Cabeza, L.F.; Jiménez, L. Multi-objective optimization coupled with life cycle assessment for retrofitting buildings. Energy Build. 2014, 82, 92-99. [CrossRef]

15. Mauro, G.M.; Hamdy, M.; Vanoli, G.P.; Bianco, N.; Hensen, J.L.M. A new methodology for investigating the cost-optimality of energy retrofitting a building category. Energy Build. 2015, 107, 456-478. [CrossRef]

16. Abdou, N.; Mghouchi, Y.E.L.; Hamdaoui, S.; Asri, N.E.L.; Mouqallid, M. Multi-objective optimization of passive energy efficiency measures for net-zero energy building in Morocco. Build. Environ. 2021, 204, 108141. [CrossRef]

17. Sharif, S.A.; Hammad, A. Simulation-based multi-objective optimization of institutional building renovation considering energy consumption, Life-Cycle Cost and Life-Cycle Assessment. J. Build. Eng. 2019, 21, 429-445. [CrossRef]

18. Ascione, F.; Masi, R.F.D.; Rossi, F.D.; Ruggiero, S.; Vanoli, G.P. Optimization of building envelope design for nZEBs in Mediterranean climate: Performance analysis of residential case study. Appl. Energy 2016, 183, 938-957. [CrossRef]

19. Kiss, B.; Szalay, Z. Modular approach to multi-objective environmental optimization of buildings. Autom. Constr. 2020, 111, 103044. [CrossRef]

20. Hopfe, C.J.; Augenbroe, G.L.; Hensen, J.L. Multi-criteria decision making under uncertainty in building performance assessment. Build. Environ. 2013, 69, 81-90. [CrossRef]

21. Ascione, F.; Bianco, N.; Stasio, C.D.; Mauro, G.M.; Vanoli, G.P. A new methodology for cost-optimal analysis by means of the multi-objective optimization of building energy performance. Energy Build. 2015, 88, 78-90. [CrossRef]

22. Asadi, E.; da Silva, M.G.; Antunes, C.H.; Dias, L.; Glicksman, L. Multi-objective optimization for building retrofit: A model using genetic algorithm and artificial neural network and an application. Energy Build. 2014, 81, 444-456. [CrossRef]

23. Bre, F.; Fachinotti, V.D. A computational multi-objective optimization method to improve energy efficiency and thermal comfort in dwellings. Energy Build. 2017, 154, 283-294. [CrossRef]

24. Shi, X.; Tian, Z.; Chen, W.; Si, B.; Jin, X. A review on building energy efficient design optimization rom the perspective of architects. Renew. Sustain. Energy Rev. 2016, 65, 872-884. [CrossRef]

25. Chegari, B.; Tabaa, M.; Simeu, E.; Moutaouakkil, F.; Medromi, H. Multi-objective optimization of building energy performance and indoor thermal comfort by combining artificial neural networks and metaheuristic algorithms. Energy Build. 2021, 239, 110839. [CrossRef]

26. Delgarm, N.; Sajadi, B.; Kowsary, F.; Delgarm, S. Multi-objective optimization of the building energy performance: A simulationbased approach by means of particle swarm optimization (pso). Appl. Energy 2016, 170, 293-303. [CrossRef]

27. Tuhus-Dubrow, D.; Krarti, M. Genetic-algorithm based approach to optimize building envelope design for residential buildings. Build. Environ. 2010, 45, 1574-1581. [CrossRef]

28. Yu, W.; Li, B.; Jia, H.; Zhang, M.; Wang, D. Application of multi-objective genetic algorithm to optimize energy efficiency and thermal comfort in building design. Energy Build 2015, 88, 135-143. [CrossRef]

29. Hamdy, M.; Hasan, A.; Siren, K. Applying a multi-objective optimization approach for design of low-emission cost-effective dwellings. Build. Environ. 2011, 46, 109-123. [CrossRef]

30. Murray, S.N.; Walsh, B.P.; Kelliher, D.; O'Sullivan, D.T.J. Multi-variable optimization of thermal energy efficiency retrofitting of buildings using static modeling and genetic algorithms-A case study. Build. Environ. 2014, 75, 98-107. [CrossRef]

31. Kusiak, A.; Xu, G.; Tang, F. Optimization of an HVAC system with a strength multi objective particle-swarm algorithm. Energy 2011, 36, 5935-5943. [CrossRef]

32. Salas-Molina, F.; Rodriguez-Aguilar, J.A.; Pla-Santamaria, D. A stochastic goal programming model to derive stable cash management policies. J. Glob. Optim. 2019, 76, 333-346. [CrossRef]

33. Bre, F.; Silva, A.S.; Ghisi, E.; Fachinotti, V.D. Residential building design optimisation using sensitivity analysis and genetic algorithm. Energy Build. 2016, 133, 853-866. [CrossRef]

34. Steuer, R.E.; Choo, E.U. An interactive weighted Tchebycheff procedure for multiple objective programming. Math. Program. 1983, 26, 326-344. [CrossRef]

35. Wu, Z.; Wang, B.; Xia, X. Large-scale building energy efficiency retrofit: Concept, model and control. Energy 2016, 109, 456-465. [CrossRef]

36. Pierre, B. Pareto (Vilfredo)—Cours d'économie politique. Rev. Conomique 1965, 16, 811-812. [CrossRef]

37. Li, X.; Malkawi, A. Multi-objective optimization for thermal mass model predictive control in small and medium size commercial buildings under summer weather conditions. Energy 2016, 112, 1194-1206. [CrossRef]

38. Tamiz, M.; Jones, D.; Romero, C. Goal programming for decision making: An overview of the current state-of-the-art. Eur. J. Oper. Res. 1998, 111, 569-581. [CrossRef]

39. Simon, H.A. Models of Man; Wiley: New York, NY, USA, 1955. 
40. Charnes, A.; Cooper, W.W. Management Models and Industrial Applications of Linear Programming; Wiley: New York, NY, USA, 1961.

41. Lee, S.M. Goal Programming for Decision Analysis; Auerbach: Philadelphia, PA, USA, 1972.

42. Ignizio, J.P. Goal Programming and Extensions (Lexington, Mass: DC Heath \& Co); Lexington Books: Lexington, MA, USA, 1976.

43. Romero, C. Handbook of Critical Issues in Goal Programming; Pergamon Press: Oxford, UK, 1991.

44. Hamta, N.; Ehsanifar, M.; Sarikhani, J. Presenting a goal programming model in the time-cost-quality trade-off. Int. J. Constr. Manag. 2021, 21, 1-11. [CrossRef]

45. Qian, S.D. Operations Research, 4th ed.; Tsinghua University Press: Beijing, China, 2012.

46. De Kluyver, C.A. An exploration of various goal programming formulations-with application to advertising media scheduling. J. Oper. Res. Soc. 1979, 30, 167-171. [CrossRef]

47. Masud, A.S.; Hwang, C.L. Interactive sequential goal programming. J. Oper. Res. Soc. 1981, 32, 391-400. [CrossRef]

48. Al-Zubaydi, A.Y. Building models design and energy simulation with google sketchup and openstudio. J. Adv. Sci. Eng. Res. 2013, 3, 318-333.

49. Hygh, J.S.; Decarolis, J.F.; Hill, D.B.; Ranjithan, S.R. Multivariate regression as an energy assessment tool in early building design. Build. Environ. 2012, 57, 165-175. [CrossRef]

50. Geyer, P.; Schlüter, A. Automated metamodel generation for design space exploration and decision-making-A novel method supporting performance-oriented building design and retrofitting. Appl. Energy 2014, 119, 537-556. [CrossRef]

51. Glodon Cost. GTJ2018 Operation Manual of Glodon BIM Civil Engineering Measurement Platform. 2018. Available online: https:/ / max.book118.com/html/2019/0521/7200124063002026shtm (accessed on 14 May 2020).

52. Goldberg, D.E. Genetic Algorithms in Search, Optimization and Machine Learning; Addison-Wesley Pub. Co.: Boston, MA, USA, 1989. [CrossRef]

53. MOHURD. Thermal Design Code of Civil Buildings (GB 50176-2016); China Architecture \& Building Press: Beijing, China, 2016.

54. MOHURD. Code of Bills of Quantities and Valuation for Construction Works (GB 50500-2013); China Architecture \& Building Press: Beijing, China, 2013.

55. Carbon Emission Factor of the Building Materials. Available online: http://www.tanpaifang.com/tanjiliang/2019/0430/63792. html (accessed on 22 March 2020). 